\title{
Editorial
}

\section{The challenges and the opportunities of letting children have their say}

\begin{abstract}
Many science communication activities identify children as their main target. There are several reasons for this, even if, quite often, they are not expressed explicitly, as if children were a somehow "natural" public for science. On the contrary, we can observe a high level of complexity in the children agenda to engage with science, and in the science institution agendas for targeting children. But this does not seem to be followed but the same level of complexity in devising science engagement activities for children. The profound transformation of the scope and understanding of science communication that we have observed in recent years, in which keywords as dialogue, participation and empowerment have become essential, has only partially touched the younger public, which remains in most cases considered as a spectator for science.
\end{abstract}

Many science communication activities identify children as their main target. There are several reasons for this, even if, quite often, they are not expressed explicitly, as if children were a somehow "natural" public for science. For example, science communication is often "naturally" conceived within an educational frame, acting in parallel or even in explicit support to the formal education system, thus making children a privileged target group.

Science is also able to display a wonderful mix of enchanting phenomena and fascinating knowledge, making it an ideal subject for family activities. Families are in fact the most numerous public of museums and science centres, and a key audience for science TV programmes: simply said, children love to learn, and parents love that children love to learn. Moreover children are often considered "natural scientists" for their capacity to look at the world with open eyes and pose authentic questions on nature (at least up to the age of about 12, when they become "corrupted", we don't know yet whether by the school system, by the approaching needs of the labour market, by their hormones, or by a combination of the three). And, last but not least, children are a constantly renewing public, and targeting them offers a particularly positive return on investment.

But there are many other reasons, underneath which lies very often the ideological mainstream of a socio-economical project for our societies. In the European case, for example, this project is represented by the Lisbon agenda and its objective to make Europe the most competitive knowledge society in the world. Under this perspective, children are targeted because they are the potential scientists of tomorrow, and therefore key actors in a society whose competitiveness is heavily determined by scientific and technological performance. 
This list could be expanded further. But if the "why" we target children is very complex and articulated, the "how" does not always follow this complexity. It presents on the contrary a high homogeneity, with a dominant presence of the "science is fun" approach, that places children in the position of spectators or at least of mere recipients, no matter how interactive the activities can be. The profound transformation of the scope and understanding of science communication that we have observed in recent years, in which keywords such as dialogue, participation and empowerment have become essential, has only partially touched the younger public. It might be true that changing the scope of science communication - from mere knowledge transfer to public debate on science and technology to public participation in the production of knowledge (to be very concise) - implies a shift in the main target group, from children to adults. But we should ask ourselves if it is necessarily so. In our opinion, this assumption needs at least to be questioned.

Is it really "natural" to exclude children from the discussion on controversial scientific issues, ethical dilemmas related to scientific applications and other "difficult" subjects related to science and technology? Are we protecting them, or are we underestimating their capacity to understand and their awareness of what is going on around them? Can we really identify an age threshold, before which children should only enjoy hands-on activities and after which they can be involved in the dialogue between science and society?

Some projects around the world have already tested new paradigms for the communication of science also in programmes dedicated to children, as radically as has been done for adults: participatory projects, (children) citizens science and other activities have been held, to treat children as individuals with opinions, goals and the capacity to pursue them. ${ }^{1}$

What are the challenges and what the opportunities? At the heart of a dialogic approach to science communication is the capacity to listen to the public. If this public are children, are we well equipped to listen to them? What can science communication gain from listening to children? What are the conditions under which listening leads to empowerment, and promotes an ownership of knowledge? What are the conditions under which listening and empowering the children can induce institutional changes in the same organizations that promote the public engagement in science, including universities and institutes of research?

The collection of comments of this issue of JCOM revolve around these questions, looking at some science communication approaches in the light of their ability to include children as protagonists, and under the perspective of the UN convention on the right of the child, which obliges us to give children a voice and listen to them on any issues affecting them.

On the background of these considerations lies the essential issue of science communication as a means to promote social inclusion. In fact, a solid, structured form of knowledge such as science can be perceived very differently by children with a higher socio-economic background (for whom science represents an opportunity for success) and those coming from disadvantaged areas or local minorities (for whom 
science can be mainly an instrument of selection for progression into higher education, strengthening the separation between a future "for them" and a future "for me").

The next PCST conference in Salvador (Bahia) is very wisely devoted to "Science communication for social inclusion and political engagement": there is no doubt that a lot of interesting reflections will emerge on this occasion, and it will be up to a journal like JCOM to ensure that these are reflected in the literature.

\title{
Matteo Merzagora and Paola Rodari
}

\section{Notes and references}

\footnotetext{
${ }^{1}$ Among JCOM published papers see, for example: L Massarani (2008), "Not in front of the children! The controversies of science and science communication for children and youth", JCOM 07(01): C02; G. Lo Iacono and A.S.A.T. de Paula (2011), "A pilot project to encourage scientific debate in schools. Comics written and peer-reviewed by young learners", JCOM 10(03): A04.
}

\begin{abstract}
Authors
Matteo Merzagora is scientific director of the TRACES science communication thinkand-do tank in Paris, and director of programs of the science culture centre Espace de sciences Pierre-Gilles de Gennes - ESPCI ParisTech. He is currently involved in several programs linking the science in society and the social inclusion agendas, and using arts and culture as a way to empower citizens with respect to scientific knowledge. Among his latest exhibitions: La science, une histoire d'humour (a 100\% crowd-sourced exhibition on science and humor) and Les invisibles (an art-science exhibition on the fascinations and the worries that science generates when it unveils new invisibles). E-mail: merzagora@gmail.com.
\end{abstract}

Paola Rodari is a project manager and content developer for the development of new science centres. She has been the project leader for the realisation of Italian science centres where she worked as leader of educational services and scientific leader for new projects. She has been funder and spokesman of THE group, the Thematic Human Interface and Explainers group of Ecsite (the European network of science museums and science centres), dedicated to the professional development of museums educators. She teaches Museum Studies in the SISSA Master's in Science Communication (http://mcs.sissa.it) and has been organizer, speaker and tutor on many international courses. She is involved in many European action-research projects aiming to develop new programmes and tools for the communication of science.

Email:paola@medialab.sissa.it.

How TO CITE: M. Merzagora and P. Rodari (2013), "The challenges and the opportunities of letting children have their say", JCOM 12(03): E. 